\title{
A CIDADANIA LGBT NAS CANDIDATURAS À PRESIDÊNCIA DA REPÚBLICA DO BRASIL EM $2018^{1}$
}

\author{
Cleyton Feitosa ${ }^{2}$
}

Resumo: Como se posicionaram os candidatos à Presidência da República do Brasil em relação à temática da diversidade sexual e de gênero nas eleições de 2018? O presente trabalho visa apresentar os resultados de uma pesquisa documental realizada sobre os Planos de Governo das 13 candidaturas presidenciais registradas no Tribunal Superior Eleitoral (TSE). Verifiquei que $69,2 \%$ das candidaturas abordaram a temática LGBT nos seus programas partidários e que, desse montante, $77,7 \%$ o fizeram de maneira positiva, apresentando propostas para a superação dos desafios ao exercício da cidadania. $\mathrm{O}$ trabalho ainda analisa as políticas públicas LGBT indicadas nos Planos de Governo de cada presidenciável que apresentou propostas para o segmento.

Palavras-chave: Democracia; Direitos Humanos; Política Institucional; Cidadania LGBT; Eleições 2018.

\section{Introdução}

Com o registro de candidaturas à Presidência da República do Brasil no Tribunal Superior Eleitoral (TSE) em 15 de agosto de 2018, tivemos acesso integral aos Planos de Governo dos presidenciáveis no complexo pleito eleitoral daquele ano. Embora pouco acessados, os Planos de Governo são documentos interessantes em termos de

\footnotetext{
${ }^{1}$ Esse trabalho é fruto de uma solicitação do Conselho Nacional de Combate à Discriminação e Promoção dos Direitos de LGBT (CNCD/LGBT). Após a apresentação dos resultados aos conselheiros, uma versão textual prévia foi publicada ainda no período eleitoral no site do Observatório das Eleições, projeto criado no âmbito do Instituto da Democracia e da Democratização da Comunicação (INCT) coordenado pelo Prof. Dr. Leonardo Avritzer (UFMG). Em seguida, foi apresentado no IX Congresso Internacional da Associação Brasileira de Estudos da Homocultura (IX CINABEH), ocorrido em novembro de 2018 em Fortaleza/CE, de onde recolheu novas contribuições que foram incluídas nesta versão para a REBEH.

${ }^{2}$ Doutorando em Ciência Política pela Universidade de Brasília - UnB. Mestre em Direitos Humanos pela Universidade Federal de Pernambuco - PPGDH/UFPE. Licenciado em Pedagogia pela Universidade Federal de Pernambuco/Centro Acadêmico do Agreste - UFPE/CAA. Autor do livro 'Políticas Públicas LGBT e Construção Democrática no Brasil' (Appris, 2017). Pesquisador do Grupo de Pesquisa RESOCIE Repensando as Relações entre Sociedade e Estado (UnB/IPOL/CNPq).
}

Vol. 01, N. 04, Out. - Dez., 2018 - www.revistas.unilab.edu.br/index.php/rebeh 
posicionamento dos partidos políticos sobre os mais variados temas, podendo auxiliar na escolha do voto a partir das afinidades entre as preferências dos eleitores e as propostas dos candidatos $^{3}$. Do ponto de vista da pesquisa, também se constituem como ricas fontes de dados já que além das propostas em um provável governo, as candidaturas expressam diagnósticos da realidade, visões de mundo sobre diferentes problemas de ordem coletiva e diferentes projetos políticos em disputa.

Um desses problemas coletivos é a forte violência dirigida contra a população de lésbicas, gays, bissexuais, travestis e transexuais (LGBT) no Brasil. Trata-se de uma maioria minorizada pelas normas hegemônicas de gênero e sexualidade que regulam corpos, afetos, identidades e performances.

Do surgimento do Movimento Homossexual Brasileiro (como então era chamado antigamente) em meados da década de 70 até os dias de hoje, esse público vem dando passos largos no que diz respeito à visibilidade da sua agenda política na opinião pública, à conquista de direitos e à penetração de suas demandas no Estado. Não foram à toa as conquistas de decisões favoráveis no Supremo Tribunal Federal (STF) em 2011 e $2018^{4}$ e a implementação de políticas públicas pelo Governo Federal a partir do Brasil Sem Homofobia no ano de 2004.

Por outro lado, esses avanços têm suscitado também reações contrárias, principalmente no Legislativo brasileiro através da bancada da bíblia (que juntamente com as bancadas do boi e da bala ${ }^{5}$ têm formado uma grande barreira de avanço civilizatório em nosso país). Mas, à despeito de toda reação que temos vivido, o Movimento LGBT tem conseguido disputar parte da política institucional, a exemplo da criação de setoriais LGBT nos partidos políticos (SANTOS, 2016a), do lançamento de candidaturas próprias (SANTOS, 2016b) e da influência sobre candidaturas majoritárias como as dos presidenciáveis.

Esse ensaio visa, portanto, analisar se e como aparece a temática da diversidade sexual e de gênero nos Planos de Governo das candidaturas à Presidência da República

\footnotetext{
${ }^{3}$ Embora reconheçamos que a formação de preferências nas democracias contemporâneas não é algo dado à priori, mas construída no plano das disputas sociais e políticas. Para uma discussão mais detida sobre as preferências ler Miguel (2015).

${ }^{4}$ Casamento igualitário e reconhecimento de demandas das pessoas trans, respectivamente.

${ }^{5}$ As bancadas da bíblia, do boi e da bala referem-se, respectivamente, ao agrupamento de parlamentares do Congresso Nacional que representam os interesses de lideranças evangélicas, ruralistas do agronegócio e defensores do armamento civil.
}

Vol. 01, N. 04, Out. - Dez., 2018 - www.revistas.unilab.edu.br/index.php/rebeh 
do Brasil nas eleições de 2018 apresentadas ao TSE. O texto está dividido, além da introdução, em uma seção metodológica, outra com a apresentação dos resultados e, por fim, com conclusões finais que fecham os achados dessa análise.

\section{Metodologia}

O método utilizado para o desenvolvimento da pesquisa foi basicamente a técnica da pesquisa documental nos moldes como é explicada por Gil (2008). Obtive acesso aos Planos de Governo das 13 candidaturas à Presidência da República do Brasil nas eleições de 2018 no site oficial do TSE. Com essa base de dados em mãos, procedi à leitura integral dos Planos buscando localizar conteúdos que fizessem menção à diversidade sexual e de gênero. À medida em que detectava tais conteúdos, os separava em um documento à parte para, em seguida, realizar a análise do conteúdo (BARDIN, 2001). A seguir, o quadro sinóptico das candidaturas registradas e dos Planos de Governo analisados:

Tabela 1 - Candidaturas presidenciais apresentadas ao TSE nas eleições de 2018 por ordem alfabética

\begin{tabular}{|c|c|c|c|}
\hline Nome & Partido & Nome da Coligação & Partidos Coligados \\
\hline 1. Álvaro Dias & PODE & Mudança de Verdade & $\begin{array}{l}\text { Podemos, PSC, } \\
\text { PRP, PTC }\end{array}$ \\
\hline 2. Cabo Daciolo & PATRI & --- & --- \\
\hline 3. Ciro Gomes & PDT & Brasil Soberano & PDT, AVANTE \\
\hline 4. Eymael & DC & --- & --- \\
\hline 5. Geraldo Alckmin & PSDB & Para Unir o Brasil & $\begin{array}{l}\text { PSDB, PTB, PP, } \\
\text { PR, DEM, } \\
\text { SOLIDARIEDADE, } \\
\text { PPS, PRB, PSD }\end{array}$ \\
\hline 6. Guilherme Boulos & PSOL & $\begin{array}{c}\text { Vamos sem Medo de } \\
\text { Mudar o Brasil }\end{array}$ & PSOL, PCB \\
\hline 7. Henrique Meirelles & MDB & Essa é a Solução & MDB, PHS \\
\hline 8. Jair Bolsonaro & PSL & $\begin{array}{c}\text { Brasil Acima de } \\
\text { Tudo, Deus Acima de } \\
\text { Todos }\end{array}$ & PSL, PRTB \\
\hline 9. João Amoêdo & NOVO & --- & --- \\
\hline 10. João Goulart Filho & PPL & --- & --- \\
\hline 11. Lula & PT & $\begin{array}{l}\text { O Povo Feliz de } \\
\text { Novo }\end{array}$ & PT, PC do B, PROS \\
\hline 12. Marina Silva & REDE & $\begin{array}{c}\text { Unidos para } \\
\text { Transformar o Brasil }\end{array}$ & --- \\
\hline
\end{tabular}

Vol. 01, N. 04, Out. - Dez., 2018 - www.revistas.unilab.edu.br/index.php/rebeh 


\begin{tabular}{|l|c|c|c|} 
13. Vera & PSTU & --- & -- \\
\hline
\end{tabular}

Fonte: Tabela elaborada pelo autor com base nos dados do TSE.

Após a leitura integral dos Planos de Governo, descartei da análise qualitativa aqueles documentos que não faziam nenhuma menção à temática da diversidade sexual e de gênero. Assim, o corpus da pesquisa foi reduzido para nove Planos de Governo que de algum modo mencionavam a questão de interesse desse estudo (diversidade sexual e de gênero). Na próxima seção serão apresentados os resultados da pesquisa.

\section{Resultados e Discussão}

Passemos ao levantamento dos Planos de Governo que abordaram a temática da diversidade sexual e de gênero, independente do teor.

Fig. 1 - Percentual da presença da temática LGBT nos Planos de Governo

$$
\begin{gathered}
\text { PRESENÇA LGBT NOS PLANOS DE } \\
\text { GOVERNO } \\
\square S i m \backsim N a ̃ o
\end{gathered}
$$

$30,80 \%$

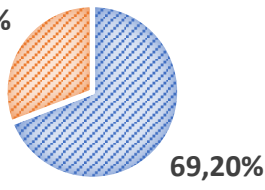

Fonte: Gráfico elaborado pelo autor com base nos Planos de Governo dos presidenciáveis.

A leitura dos Planos de Governo demonstrou que quase $70 \%$ das candidaturas à Presidência da República do Brasil no pleito eleitoral de 2018 abordaram a temática LGBT revelando grande penetração da pauta na sociedade política, possivelmente um reflexo das interações da militância com o Estado, para além de outros fatores como a inserção do tema nas redes sociais, nas representações artísticas, culturais e midiáticas. Do total de candidaturas registradas, apenas Álvaro Dias (PODE), Eymael (DC), Henrique 
Meirelles (MDB) e João Amoêdo (NOVO) ignoraram a questão de interesse. Veremos a seguir a qualidade do teor abordado nos documentos (se negativo ou positivo) ${ }^{6}$.

Fig. 2 - Percentual da qualidade do teor nos Planos de Governo

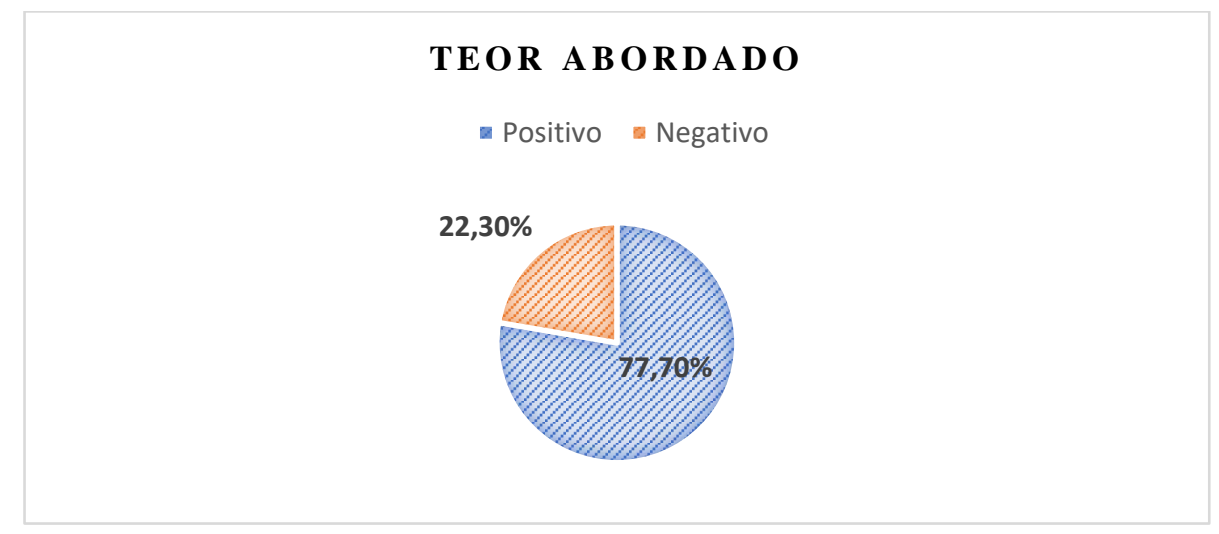

Fonte: Gráfico elaborado pelo autor com base nos Planos de Governo dos Presidenciáveis.

Como é possível notar, a maior parte das candidaturas abordaram positivamente a temática LGBT a partir de diagnósticos sobre a realidade dessa população no país seguidos de propostas para a superação dos desafios. Das nove candidaturas que abordaram a questão LGBT apenas duas $(22,3 \%)$ o fizeram de maneira negativa. Tratamse dos Planos de Governo de Jair Bolsonaro (PSL) e Cabo Daciolo (PATRI).

O Plano de Governo do então candidato Jair Bolsonaro na seção "Educação" afirmou que o "conteúdo e método de ensino precisam ser mudados. Mais matemática, ciências e português, SEM DOUTRINAÇÃO E SEXUALIZAÇÃO PRECOCE”, assim mesmo em letras maiúsculas (Plano de Governo - Jair Bolsonaro, 2018, p. 41). Tratam-se das principais bandeiras empunhadas pelo Escola Sem Partido e pela retórica da Ideologia de Gênero (MISKOLCI e CAMPANA, 2017).

Já Cabo Daciolo em seu Plano de Nação para a Colônia Brasileira, como é intitulado o seu Plano de Governo, disse que

[...] Não é possível conceber que a família em seus moldes naturais seja destruída, que a ideologia de gênero e a tese de legalização do aborto sejam disseminadas em nossa sociedade como algo normal; que até mesmo a pedofilia seja estimulada de forma sorrateira por aqueles que querem destruir o que há de mais sagrado na sociedade, simplesmente para dominar e oprimir. Isso não

\footnotetext{
${ }^{6}$ Por teor positivo entende-se aqueles conteúdos que propõem iniciativas de promoção da cidadania da população LGBT. Por teor negativo, ao contrário, entende-se aqueles conteúdos que reforçam o lugar subalterno da população LGBT na sociedade.
}

Vol. 01, N. 04, Out. - Dez., 2018 - www.revistas.unilab.edu.br/index.php/rebeh 
é laicidade. É a desmoralização da Pátria (Plano de Governo - Cabo Daciolo, p. 41).

Embora ambos não façam menção explícita à população LGBT, trata-se claramente de uma ofensiva contra as agendas políticas da militância, principalmente aquelas que reivindicam ações de inclusão e respeito à diversidade sexual e de gênero nas escolas transmutadas no pânico moral "ideologia de gênero": um plano malévolo de feministas e LGBT para converter crianças em homo e transexuais e destruir a sagrada família nuclear heterossexual. Outro estigma historicamente imposto à população LGBT, a pedofilia, também é mobilizado por Daciolo, indicando que, ainda que de modo implícito, trata-se de clara menção ao segmento.

Felizmente, quase $80 \%$ dos Planos de Governo que abordaram a temática LGBT o fizeram de maneira positiva, ou melhor, propositiva, apresentando diagnósticos, reconhecimentos e propostas para combater a LGBTfobia. Ciro Gomes (PDT), Geraldo Alckmin (PSDB), Guilherme Boulos (PSOL), João Goulart Filho (PPL), Lula (PT), Marina Silva (REDE) e Vera (PSTU), de modo mais ou menos detalhado, comprometeram-se a incluir a população LGBT em um provável governo. Vamos a análise individual de cada Plano.

\section{Ciro Gomes (PDT)}

O Plano de Governo do cearense mais conhecido pelo seu interesse e inserção nos debates sobre a economia nacional apresentou 14 propostas para a população LGBT sendo 13 delas na seção "respeito à população LGBTI" e 1 na seção "respeito à juventude" do documento. Dentre dessas propostas, destacam-se a promessa de criação de uma Secretaria Nacional de Políticas Públicas LGBT, algo até então inédito na implementação de políticas para o segmento no país; implementação efetiva do Plano Nacional LGBT ${ }^{7}$; criação de meios para coibir crimes LGBTIfóbicos; fortalecimento do Disque $100^{8}$; inclusão da temática no Plano Nacional de Educação (PNE); articulação para criar um Estatuto das Famílias (no plural) e da Diversidade ${ }^{9}$; ações na saúde e apoio à legislações

\footnotetext{
${ }^{7}$ Documento lançado em 2009 ainda no Governo Lula.

${ }^{8}$ Canal de denúncias de violações de direitos humanos gerido pelo Ministério de Direitos Humanos.

${ }^{9}$ Em oposição ao Estatuto da Família apresentado por parlamentares da bancada evangélica que exclui do reconhecimento parental famílias compostas por pessoas do mesmo sexo e gênero.
}

Vol. 01, N. 04, Out. - Dez., 2018 - www.revistas.unilab.edu.br/index.php/rebeh 
específicas que beneficiariam a população LGBT. Chama atenção no seu Plano a indicação de adoção de medidas concretas na máquina públicas em vez de promessas de cunho mais genérico e abstrato como aconteceu no caso de outras candidaturas ${ }^{10}$.

\section{Geraldo Alckmin (PSDB)}

De maneira muito parcimoniosa, o Plano de Governo do tucano prometeu apenas “estabelecer um pacto nacional para a redução de violência contra idosos, mulheres e LGBTI e incentivar a criação de redes não-governamentais de apoio ao atendimento de vítimas de violência racial e contra tráfico sexual e de crianças" (Plano de Governo Geraldo Alckmin, 2018, p. 11). É interessante notar as concepções neoliberais do PSDB que responsabilizam a sociedade civil, por meio de organizações não-governamentais, pelo atendimento das vítimas de violações de direitos humanos, visão que remete à década de 90 e ao Governo Fernando Henrique Cardoso (1995-2002).

\section{Guilherme Boulos (PSOL)}

Com 238 páginas, um número muito acima dos demais, o Plano de Governo do ativista do Movimento dos Trabalhadores Sem Teto e candidato pelo PSOL, Guilherme Boulos, apresenta um rol vasto de propostas para a população LGBT. Para essa pesquisa o documento foi lido na íntegra, mas uma simples busca pela palavra-chave 'LGBT' no arquivo resultou num total de 73 resultados. O texto revelou que a temática da diversidade sexual e de gênero, mais do que um tópico ou uma linha de ação, assume centralidade em todas as políticas sociais previstas em um eventual governo PSOLista. Assim, as propostas apareceram em uma seção específica chamada "Diversidade importa! Um programa para a cidadania LGBTI" que se desdobram em subseções como "família”, "pessoas trans", “escolas”, “emprego, renda e moradia", "segurança” e "saúde integral”. Além disso, em outras seções também são apontadas ações para o segmento LGBT (educação, saúde, segurança, assistência social, cultura, comunicação e juventude). Com efeito, é o Plano que mais se aproxima do conjunto de reivindicações e demandas do Movimento LGBT.

${ }^{10}$ Agradeço a Gustavo Gomes da Costa Santos (UFPE) que me chamou atenção para esse ponto quando da apresentação dessa pesquisa no IX Congresso Internacional da ABEH no contexto do ST 14 - Diversidade Sexual e de Gênero e Política Institucional na Contemporaneidade.

Vol. 01, N. 04, Out. - Dez., 2018 - www.revistas.unilab.edu.br/index.php/rebeh 
Dentre as inúmeras propostas, destaco o seguinte trecho que na minha avaliação sintetizou o projeto político da candidatura: "Garantir a cidadania da população LGBTI como política de Estado, que jamais será relegada a um segundo plano ou negociada em troca de acordos políticos, eleitorais ou de governabilidade" (Plano de Governo - Guilherme Boulos, 2018, p. 63).

\section{João Goulart Filho (PPL)}

O Plano de Governo de João Goulart Filho não apresentou nenhum diagnóstico sobre a realidade da população LGBT, mas trouxe no ponto 18 do documento que sua política seria intolerante com qualquer tipo de discriminação. Suas propostas para a população LGBT são detalhadas na página 13 e concentram-se mais na promessa de qualificação do atendimento no serviço público. De fato, a formação continuada de servidores públicos e o combate à LGBTfobia institucional são ações necessárias para a garantia de direitos, mas isoladamente tal combate não é suficiente para prover mudanças culturais de maneira mais enfática.

\section{Fernando Haddad (PT)}

Apesar de aparecerem propostas nos eixos de educação, saúde, segurança e políticas para mulheres, é na seção "afirmação de direitos" que apareceu a maioria das ações voltadas para o segmento LGBT no caso do plano petista. Assim, o documento se comprometeu a promover o direito à vida, ao emprego e à cidadania LGBTI+ com prioridade para as pessoas em situação de pobreza. Falou em superação da violência e fortalecimento do Sistema Nacional LGBTI+ por meio da instituição de uma Rede de Enfrentamento à Violência contra LGBTI+; falou também em fortalecimento da Política de Saúde Integral e em ações na educação e no combate à mortalidade de pessoas trans. O Plano de Governo do PT prometeu ainda nacionalizar o Transcidadania, política pública municipal da Prefeitura de São Paulo na gestão Haddad que ficou conhecida pelo pioneirismo em incluir pessoas trans nos serviços municipais junto com uma bolsa visando à elevação educacional e qualificação profissional de travestis e transexuais em situação de vulnerabilidade econômica e social.

Vol. 01, N. 04, Out. - Dez., 2018 - www.revistas.unilab.edu.br/index.php/rebeh 


\section{Marina Silva (REDE)}

Evangélica, Marina é conhecida pela ambiguidade das suas posições especialmente em temas considerados "polêmicos" na sociedade. Nas eleições presidenciais de 2014, quando também era candidata à Presidência do Brasil, recuou nas propostas que havia feito para a população LGBT após reação de setores opositores aos direitos LGBT. Em 2018, seu Plano de Governo é mais assertivo: falou em combate à discriminação nas escolas; em garantia e ampliação do acesso a serviços de saúde integral; em políticas de prevenção da violência e em garantir acesso ao mercado de trabalho. Declarou ainda que o Plano Nacional LGBT (aquele lançado em 2009) seria considerado na elaboração de políticas públicas; prometeu acatar a demanda por uma legislação que regulamentasse o casamento civil igualitário e defendeu tratamento igual para casais homoparentais adotantes.

\section{Vera Lúcia (PSTU)}

Intitulado 16 pontos de um programa socialista para o Brasil contra a crise capitalista, o Plano de Governo do PSTU apresentou propostas para a população LGBT no $15^{\circ}$ ponto. Nele, o PSTU defendeu a criminalização da LGBTfobia; o reconhecimento das identidades trans; a despatologização da transexualidade; a regulamentação do nome social de travestis e transexuais; a garantia de atendimento médico pelo Sistema Único de Saúde (SUS) e uma educação que ensinasse o respeito à diversidade. As propostas são concluídas com um "não ao Escola Sem Partido", projeto de lei que visa censurar conteúdos nas instituições educacionais e perseguir professores e professoras (Plano de Governo - Vera Lúcia, 2018, p. 4).

\section{Conclusões}

O presente trabalho teve por objetivo analisar as posições dos candidatos à Presidência da República do Brasil nas eleições de 2018 em relação à temática da diversidade sexual e de gênero. A opção metodológica adotada foi realizar uma análise documental nos 13 Planos de Governo registrados no TSE. Na análise, foi verificado que

Vol. 01, N. 04, Out. - Dez., 2018 - www.revistas.unilab.edu.br/index.php/rebeh 
69,2\% das candidaturas abordaram a temática LGBT nos seus programas partidários e que, desse montante, $77,7 \%$ o fizeram de maneira positiva, apresentando propostas para a superação dos desafios ao exercício da cidadania.

Esses dados revelam, para além de outros aspectos, uma expressiva penetração das agendas políticas do Movimento LGBT para a política institucional, sobretudo, para os partidos políticos, responsáveis exclusivos pelo lançamento de candidaturas que disputam votos para a ocupação de cargos executivos e legislativos do Estado visando deter nacos expressivos do poder político nas democracias contemporâneas.

Assim, tal estudo aponta como futura agenda de pesquisa análises mais detidas sobre as relações causais que possibilitaram tão notável penetração na arena institucional. Uma hipótese sobre essa penetração é a criação de setoriais LGBT nos partidos políticos em paralelo às transformações culturais mais amplas e à força que o Movimento LGBT construiu nas últimas décadas no Brasil.

\section{Referências}

BARDIN, Laurence. Análise de Conteúdo. Lisboa: Relógio D’água Editores, 2001.

GIL, Antônio Carlos. Métodos e Técnicas de Pesquisa Social. 6 ed. São Paulo: Atlas, 2008.

MIGUEL, Luis Felipe. Autonomia, paternalismo e dominação na formação das preferências. Opinião Pública, v. 21, n. 3, 2015.

MISKOLCI, Richard; CAMPANA, Maximiliano. "Ideologia de gênero": notas para a genealogia de um pânico moral contemporâneo. Revista Sociedade e Estado, v. 32, n. $3,2017$.

SANTOS, Gustavo Gomes da Costa. Diversidade sexual, partidos políticos e eleições no Brasil contemporâneo. Revista Brasileira de Ciência Política, n. 21, 2016b.

- Movimento LGBT e partidos políticos no Brasil. Contemporânea - Revista de Sociologia da UFSCar, v. 6, n. 1, 2016a.

\section{LGBT CITIZENSHIP IN THE CANDIDACIES TO THE PRESIDENCY OF THE REPUBLIC OF BRAZIL IN 2018}

Vol. 01, N. 04, Out. - Dez., 2018 - www.revistas.unilab.edu.br/index.php/rebeh 
Abstract: How did the candidates for the Presidency of the Republic of Brazil stand on the issue of sexual and gender diversity in the 2018 elections? The present paper aims to present the results of a documentary research carried out on the Government Plans of the 13 presidential candidates registered in the Superior Electoral Court (TSE). I verified that $69.2 \%$ of the candidates approached the LGBT theme in their party programs and that, of this amount, $77.7 \%$ did so in a positive way, presenting proposals for overcoming the challenges to the exercise of citizenship. The work also analyzes the LGBT public policies indicated in the Government Plans of each presidential candidate who presented proposals for the segment.

Keywords: Democracy; Human Rights; Institutional Policy; LGBT Citizenship; Elections 2018.

Recebido em: 01/12/2018

Aceito em: 10/01/2019 